\title{
Physiology and Pathology of Blood
}

$\mathrm{T}$ HE active state of research on blood was well shown by the symposium held at Aberdeen on September 6 by Section I (Physiology) of the British Association. The four papers which were presented at the meeting ranged from matters of practical importance to medicine, such as the incidence of anæmia amongst the poor of Aberdeen, to problems of -at the moment-purely scientific interest such as the molecular weight of the blood pigment, hæmoglobin, in different species ; this short account of the discussion may well begin at the medical angle of the discussion, and travel gradually over to the more academic aspects.

Prof. L. S. P. Davidson (Aberdeen) emphasised the importance of nutrition in the etiology of blood diseases. As regards the anæmias which arise from nutritional diseases, these can be sharply divided into two groups : (a) A group of diseases, which are severe, though comparatively rare in incidence, and respond to feeding with liver or liver extract but not to iron. (b) An extremely common group with low mortality but high loss of economic efficiency. These respond to feeding with iron. A deficiency of iron or of the specific anti-anæmia factor found in liver may occur through (i) actual deficiency of the factors, or of their precursors, in the diet; (ii) imperfect digestive processes either leading to failure in the manufacture of the factors or rendering them unavailable; under this heading specific deficiency in gastric secretion has been shown by Castle and others to be of clear importance; (iii) defective absorption from the intestine; (iv) demand being excessive, though the supply is normal, as in pregnancy.

Prof. Davidson has found amongst the poor of Aberdeen that roughly 50 per cent of adult women and of infants up to the age of one year are anæmic, though children between the ages of five and fourteen years and adult men are rarely so. The diet was the same in all these cases, but was relatively low in iron : the anæmia in the women and young infants is therefore attributed mainly to the excessive demand for iron in these two cases, due either to rapidity of growth or to loss of blood at child-bearing age or menstrual periods. Prof. Davidson concluded by describing the steps which a practising physician should take when faced with a case of anæmia.

The main theme of the paper by Prof. J. Barcroft (Cambridge) was the oxygen supply to the blood of the developing foetus. At the beginning of gestation, the placenta is large relative to the size of the foetus, but the growth of the fœetus soon catches up with the placenta, and by term it may well be that the fœtus has outgrown its commissariat.

The matter has been investigated quantitatively by measurement of the oxygen content of maternal and fœetal blood. Several compensatory mechanisms seem to have been adopted to cope with the relatively poor conditions of oxygen supply to the foetus. (i) The maternal blood becomes more acid, thus being enabled to part with its oxygen more readily. (ii) The hæmoglobin of the fœetus differs from that of the mother in that it has, under identical conditions, a distinctly greater affinity for oxygen. (iii) In certain animals (for example, rabbit) the maternal and fotal blood vessels are anatomically arranged in such a way as to ensure maximum diffusion of oxygen from the maternal blood to the fotal blood. The extraordinary efficiency of these arrangements is shown by observations on the oxygen content of the blood returning from the uterus to the venous system of the mother. As pregnancy advances, the content sinks until at term the blood is almost denuded of oxygen.

Even so, the oxygen in the foetal blood feeding the foetal organs does not reach a level as high as would be found in the arteries of a man at the top of Mount Everest; it is doubtful indeed whether the foetal oxygen level would be enough to maintain consciousness in the born animal. The foetus, however, appears to be better off, in that the oxygen consumption of its tissues, per unit weight, may be only about a third of the oxygen consumption per unit weight after birth.

Dr. F. J. W. Roughton (Cambridge) gave a summary of recent work on the transport of carbon dioxide in blood from the tissues to the lungs. The pioneer work of Henriques in 1928 first directed attention to the need for studying the kinetics of the reactions of carbon dioxide in blood. This new orientation has resulted in two new lines of work.

(a) The discovery of an enzyme in the red blood corpuscles capable of accelerating both phases of the reversible reaction carbonic acid $\Rightarrow$ carbon dioxide + water. The enzyme has been separated in a high state of activity, and has been given the name carbonic anhydrase. Without this enzyme, most of the carbon dioxide to be eliminated from the animal could only escape from the blood at about one fiftieth of the rate at which it is actually excreted in the expired air. The amount of enzyme in the corpuscles is, however, sufficient to accelerate the rate of carbon dioxide elimination about a thousandfold, if the activity of the enzyme in the corpuscle is the same as in solution. The enzyme is not present in appreciable amounts in the normal blood plasma ; its absence therefrom means that, whilst the blood is actually passing through the capillaries, that part of it which is in closest proximity to the tissues, that is, the plasma, suffers even less change in acidity than had been hitherto thought. Nor is the enzyme present in most organs: Dr. Roughton gave reasons why its presence in the actual tissues would reduce rather than increase the rate of removal of carbon dioxide by the blood. Organs where its presence would be, however, an advantage, are those in which bicarbonate, as well as carbon dioxide, is excreted, such as the pancreas (via the pancreatic juice). Here the enzyme is found in large quantities.

(b) The demonstration of a direct reversible reaction between carbon dioxide and hæmoglobin of a carbamino type, namely, $\mathrm{HbNH}_{2}+\mathrm{CO}_{2}=$ $\mathrm{HbNHCOOH}$. The indirect evidence for the occurrence of this reaction in blood has recently been strengthened by the work of Ferguson and Roughton, who claim to have separated and estimated the compound by taking advantage of the fact that its barium salt is soluble and stable in alkaline solution. Owing to the greater ease with which reduced hæmoglobin forms such compounds than oxyhæmoglobin does, an appreciable fraction, possibly 20 per cent, of the carbon dioxide carried by the blood during the respiratory cycle is believed to be transported via this carbamino- $\mathrm{CO}_{2}$-hæmoglobin mechanism, 
which works quite independently of carbonic anhydrase. Dr. Roughton, in a concluding survey of the present experimental evidence, suggested that there might be at least one more chemical mechanism for carbon dioxide transport in blood besides those already postulated.

Dr. G. A. Millikan (Cambridge) gave a useful résumé of Svedberg's work upon the molecular weight of the respiratory pigments. The values obtained in different animals range from 17,000 in the Chironomus larva to $5,000,000$ in the edible snail and most gastropods. The physiological significance of the enormous variation was discussed. Dr. Millikan then described in detail the properties of the newly isolated muscle hæmoglobin, with particular emphasis upon the striking respects in which it differs, as regards its reactivity, from blood hæmoglobin. This led him finally to a survey of present theories as to the nature of the equilibrium between oxygen and hæmoglobin.
F. J. W. R.

\section{Distribution of Marine Animals and the History of the Continents}

$\mathrm{H}^{\mathrm{o}}$ W the past history of the great land and water masses of the earth's crust is reflected in the distribution of many marine animals was the subject of an important paper read by Prof. J. Versluys on September 7 before Section D (Zoology) of the British Association meeting in Aberdeen.

Prof. Versluys directed attention to the fact that the presence of a considerable number of closely allied marine animals and even specifically identical ones on both sides of Central America and in the Indian Ocean and European Atlantic points conclusively to the presence of former sea connexions linking up the Atlantic, the Pacific and the Indian Oceans. These connexions lay across Central America and through a bygone sea called Thetys, along the region where Asia and Africa now unite. In elaborating this thesis, he dealt mainly with the curious distribution of a small family of deep-water horny corals, the Primnoids.

In spite of the great land barrier now separating them, the Primnoid fauna of the European Atlantic is very similar to that of the Indo-Malayan seas, every species in the one region being represented by corresponding and, in part, closely allied species in the other. This is due to the fact that these two regions were in communication by way of the Thetys until the middle of the Tertiary period - a date so recent that no great changes in the Primnoid fauna have since then taken place.

The West Indian Primnoids, on the other hand, differ more widely from the European ones than do those of the Indo-Malayan region. Prof. Versluys suggested that this is explained by the intervention of the big Atlantic basin which, for Primnoids with their very ineffective means of dispersal, must act as a considerable barrier to distribution. Nevertheless, the difference between the West Indian and European Primnoids, though considerable, is not so great as might. on this account have been expected. The Central Atlantic formerly had a continuous southern coast, Brazil and West Africa being united, so that conditions for dispersal between European seas and the West Indies were more favourable in times past than they are now.

Contrary also to what one would expect, the West Indian fauna of Primnoids bears but little resemblance to that of the American Pacific coast, no closely allied species being known from both regions. This applies not only to the Primnoids of these regions but also to the Gorgonacean corals as well. The old Central American connexion was, for some reason, not favourable to the distribution of corals across it.

Again, the American Pacific fauna of Primnoids shows no close relationship with the Indo-Malayan and Japanese fauna. There are a few species in common-indicating a migration across, or more probably around, the Pacific-but a number of important genera have very different species in the two regions, proving that, on the whole, distribution has been restricted and that these faunas must have been separated by the large Pacific basin for a very long time.

In view of these findings, Prof. Versluys is confident that Central America is, and has been, the most formidable distributional barrier encountered by the circum-tropical fauna of Primnoids. The Pacific Ocean also was, and is, an important barrier, but the present obstacle provided by the Africa-Asia continent was absent in pre-Tertiary times when the Thetys offered favourable conditions for the dispersal of Primnoids--so much so that Indo-Malayan forms seem to have reached the West Indies by way of this ancient sea and the then smaller and circum. scribed Atlantic.

In support of these conclusions, comparison was made with the distribution of sea urchins. In spite of the fact that these animals live in shallower water (where stronger currents usually occur) than do the Primnoids, and have specialised pelagic larval stages of some duration which can be transported over long distances by water movement, the sea urchin faunal regions in the tropics and sub-tropics are the same as those of the Primnoids. The Atlantic again has proved but a feeble barrier. Of about eighty West Indian species, 19 are found also in the European Atlantic. On the other hand, there is no speeies of sea urchin known from both sides of Central America, and the tropical American Pacific coast has no species in common with the Indo-Malayan region.

The Primnoid fauna of the southern oceans also has a curious distribution, the explanation for which must be sought in the geological formations of earlier times. The southern Primnoids, especially those of the genus Primnoella, are found at a number of stations widely separated from one another by stretches of sea that must be scarcely passable for these corals with their very limited means of distribution. Moreover, of the entire southern fauna of Primnoids, only two-species of Parathonarellaare recorded from South Africa. The simplest explanation of this curiously scattered distribution, according to Prof. Versluys, is offered by Wegener's well-known theory of the splitting, up of a southern continental mass known as Gondwanaland, the parts of which drifted away from one another to form South America, Australia, Africa, part of India and the antaretic continent, with some intermediate small islands representing parts that split off from the drifting mainlands and were left behind.

G. A. S. 